\title{
Arrive, survive and thrive: essential stages in the re-colonization and recovery of zooplankton in urban lakes in Sudbury, Canada
}

\author{
Norman D. YAN, ${ }^{1 *}$ John BAILEY, ${ }^{2}$ James C. McGEER,${ }^{3}$ Marina M. MANCA,${ }^{4}$ Wendel (Bill) KELLER, ${ }^{2}$ \\ Martha P. CELIS-SALGADO, ${ }^{1}$ John M. GUNN ${ }^{2}$
}

\begin{abstract}
${ }^{1}$ Biology Department, York University, Toronto, Ontario, and Dorset Environmental Science Centre, Box 39, Dorset P0A 1E0, Ontario, Canada; ${ }^{2}$ Vale Living with Lakes Centre, Laurentian University, Sudbury P3E 2C6, Ontario, Canada; ${ }^{3}$ Department of Biology, Wilfrid Laurier University, 75 University Ave. W, Waterloo N2L 3C5, Ontario, Canada; ${ }^{4}$ National Research Council, Institute of Ecosystem Study, Largo Tonolli 50, 28922 Verbania Pallanza (VB), Italy

*Corresponding author: nyan@yorku.ca
\end{abstract}

\begin{abstract}
The recovery of lakes from severe, historical acid and metal pollution requires that colonists of extirpated species arrive, survive and subsequently thrive. We employed 40 year records from weekly to monthly crustacean zooplankton samples from Middle and Clearwater lakes near Sudbury, Canada, to identify the main mechanistic bottlenecks in this recovery process. While both lakes now have circum-neutral pH, acidity decreased more rapidly in Middle Lake because of past liming interventions, while Clearwater Lake, being larger and supporting more housing, likely receives more zooplankton colonists than Middle Lake. Community richness increased much faster in Middle Lake than in Clearwater Lake, at 1.6 vs 0.9 species decade ${ }^{-1}$, respectively. Richness has recovered in Middle Lake, when assessed against a target of 9-16 species collection ${ }^{-1}$ determined from regional reference lakes, but it has not yet recovered in Clearwater Lake. Species accumulation curves and a metric of annual persistence show that this difference is a product not of greater rates of species introduction into Middle Lake, but rather to their greater annual persistence once introduced. Greater annual persistence was associated with better habitat quality (i.e., lower acid and metal toxicity) in Middle Lake, particularly early in the record, and lower planktivore abundance, more recently. These results support a growing consensus that ecological recovery of zooplankton from acidification and metal pollution does not depend strongly on propagule introduction rates which are adequate, but rather on propagule persistence, in lake-rich, suburban landscapes such as those near Sudbury.
\end{abstract}

Key words: Liming; zooplankton; ecological recovery; species richness; Sudbury; species persistence.

Received: April 2015. Accepted: June 2015.

\section{INTRODUCTION}

While the control of atmospheric sulphur dioxide, and to a lesser extent, nitrogen oxide emissions are the only effective permanent management strategies to curb damage to lakes and rivers caused by acid rain, several nations have chosen to speed the recovery process by adding neutralizing agents, commonly powdered limestone, to acidified waters and watersheds. This management procedure is commonly called liming. While Scandinavian nations implemented the largest liming programs (Svenson et al., 1995), there were also more restricted liming programs in Canada, especially near Sudbury, Ontario (Dillon et al., 1979; Lautenbach, 1987; Gunn, 1995), and in Lago d'Orta in Italy (Bonacina, 2001). These liming programs successfully lowered lake acidity and associated metal concentrations, and have been accompanied, for example in Sudbury lakes, by promising signs of biological recovery for phytoplankton (Winter et al., 2008), zooplankton (Yan et al., 1996a), and fish (Gunn et al., 1988). Nonetheless, in general, ecological recovery has trailed water quality recovery, often by decades (Clair and Hindar, 2005; Gray and Arnott, 2009), and, with the possible exception of phytoplankton, has to date been less complete at the community level. This is not really a surprise. Added neutralizing agents immediately lower acidity and change metal speciation and solubility. Hence, water quality improvement may be rapid, depending only on the initial lake acidity, lake water renewal times and the difference between lime dosage rates and continuing rates of acid input. In contrast, poor water quality is only one of several possible bottlenecks to the recovery of biota (Keller and Yan, 1998; Gray and Arnott, 2009). Thus ecological recovery is never an immediate consequence of water quality restoration following liming (Keller et al., 1999).

What are the plausible processes that regulate recovery of biota from a pollution episode? If the episode was: i) shorter than the duration of fertility of individuals in the community, ii) smaller than the region of strong metacommunity dynamics, and iii) not severe enough to raise death rates of reproductive members of the community much above birth rates, then populations will shrink but will not be locally extirpated. Once the brief, localized 
polluting episode ends, birth rates of the residual population supplemented by immigration from the meta-community should exceed death plus emigration rates; hence, populations will regrow to historic levels and presumably persist over the long term, i.e. they will recover. For these reasons, recovery has proceeded fastest in those Sudbury lakes where acidification and metal pollution were relatively modest. For example, the complete recovery of zooplankton followed liming of the moderately damaged Nelson Lake in less than a decade, while the more severely acidified Hannah and Middle lakes had not recovered over three decades after liming (Yan et al., 1996a; Palmer et al., 2013). The damage to Middle and Hannah lakes had been severe and long-lasting (Scheider et al., 1975; Dillon et al., 1979) and zooplankton paleoecological profiles (Labaj et al., 2014), coupled with long-term monitoring data (Yan and Strus, 1980) indicated many local populations had been extirpated. While liming dramatically improved habitat quality in Middle and Hannah lakes, recovery of their lost populations faced several additional mechanistic bottlenecks (Gray et al., 2012). For a lost population to recover, colonists must arrive in numbers above Allee effect thresholds that could inherently limit establishment (Yan et al., 2003). These colonists must then survive introduction, i.e. the waters must no longer be toxic, and there must then be sufficiently few ecological impediments (from established competitors, predators, parasites, etc.) that founding populations can grow to target levels (Yan et al., 2003). In simple terms, when local populations have disappeared, colonists must arrive, survive and thrive, for populations to recover. Incagnone et al. (2015) and Gray et al. (2012) provide evidence that all of these stages may come into play, respectively, during the colonization of new or ephemeral habitats and the recovery of zooplankton from acidification, and any one of these stages could, in theory, be a major bottleneck to recovery in particular lakes or at particular times.

Here, our objectives were: i) to take advantage of long-term monitoring data to propose simple methods that can be used to identify which mechanistic bottlenecks to the recovery of zooplankton species occur in different lakes; then, ii) using these methods, to determine if different mechanisms control the recovery of crustacean zooplankton in two of Sudbury's most severely damaged urban lakes, Clearwater and Middle lakes, the latter of which was limed in 1973.

The zooplankton of Sudbury's urban lakes were particularly heavily damaged by acid and metal pollution (eg. Yan and Strus, 1980; Keller and Yan, 1991). Recent work in these lakes (Palmer et al., 2013), proves that the communities of zooplankton are recovering, but that recovery is incomplete, both because of lingering metal toxicity (Yan et al., 2004; Valois et al., 2010, 2011; Webster et al.,
2013) and/or unusually large populations of pelagic macro-invertebrate predators (Yan et al., 1991) or planktivorous fish (Webster et al., 2013; Gray and Arnott, 2009). Even though Middle Lake had been severely acidified and metal contaminated for decades, and many of its zooplankton populations were extirpated, Yan et al. (2004) noted that its copepod assemblage had completely recovered by 1996 following its 1973 liming. It had lost two acidophilic taxa, and gained populations of 5 species of calanoids and cyclopoids whose numbers were large enough that the copepod assemblage could not be distinguished, after 1996, from those of reference lakes that had never acidified. In contrast, neither the Cladoceran nor the Copepod assemblage of Clearwater Lake had recovered by 2007 , nor had the cladoceran community of Middle Lake recovered by 2007 (Palmer et al., 2013). Here we employ the 4 decade zooplankton time series from Middle and Clearwater lakes to propose simple, univariate community metrics based on species richness that can be used to compare the recovery trajectories in lakes in ways that can aid identification of which among the potential mechanistic bottlenecks are likely limiting recovery. In particular we examine the hypothesis that the more rapid recovery of species richness in Middle Lake than in Clearwater Lake that Yan et al. (2004) and Palmer et al. (2013) described is attributed not to greater colonist arrival rates, but to the greater ability of these colonists to survive and thrive in Middle Lake, both because its waters are less toxic and it supports fewer planktivorous fish

\section{METHODS}

\section{Study lake descriptions, field and laboratory methods}

Clearwater Lake $\left(46^{\circ} 22^{\prime} \mathrm{N}, 81^{\circ} 03^{\prime} \mathrm{W}\right)$ and Middle Lake ( $\left.46^{\circ} 23^{\prime} \mathrm{N}, 81^{\circ} 06^{\prime} \mathrm{W}\right)$ are relatively small ( 77 ha and 28 ha, respectively), and oligotrophic lakes, with a total phosphorus level of 5-7 $\mu \mathrm{g} \mathrm{L}^{-1}$, in the 1970s (Yan, 1979) and three decades later (Palmer et al., 2013). Their geological setting and limnology are detailed in Scheider et al. (1975), Dillon et al. (1979), and Yan and Miller (1984). Both lakes were very acidic in 1973, when our work began, with ice-free season average $\mathrm{pH}$ levels of 4.2 and 4.5 , respectively (Yan, 1979). Middle Lake is $5 \mathrm{~km}$ from the largest active smelter in Copper Cliff, while Clearwater Lake is $12 \mathrm{~km}$ away; hence, Middle Lake had higher levels of $\mathrm{Cu}\left(496\right.$ vs $\left.98 \mu \mathrm{g} \mathrm{L}^{-1}\right)$ and $\mathrm{Ni}(1060$ vs $280 \mu \mathrm{g}$ $\mathrm{L}^{-1}$, respectively) than did Clearwater Lake (Yan and Strus, 1980) in 1973. On average, a standard count of a minimum of 250 individuals produced an annual average of 8-12 species (mean $\pm 2 \mathrm{SD}$ ) of crustacean zooplankton per daily composite in 22 non-acidic, oligotrophic, softwater lakes in Ontario in the 1980s (Yan et al. 1996a), but Middle and Clearwater lakes had much lower, and very similar crustacean species richness levels of 3.4 and 3.6 
taxa collection ${ }^{-1}$ in 1973. Their zooplankton assemblages were severely damaged, with collections dominated by one bosminid and one chydorid species, plus Cyclops vernalis (Yan and Strus, 1980). Middle and Clearwater lakes are in a lightly developed, suburban region of the municipality of Sudbury, Ontario, Canada. This is a lake-rich region, so many potential sources of colonists are nearby. Zooplankton spread naturally and quite rapidly among lakes and ponds (Cáceres and Soluk, 2002; Audet et al., 2013). However, as has been well demonstrated for the non-native spiny water flea (Weisz and Yan, 2010), people also spread zooplankton over the landscape, during their recreational activities (Kelly et al., 2013). Clearwater Lake now has 60 permanent dwellings and a large children's summer camp on its shores, while Middle is less developed, with only 26 homes and cottages.

As part of a study to determine if Sudbury lakes could recover if acid input rates were reduced, Middle Lake was limed with $20 \mathrm{t}$ of $\mathrm{CaOH}_{2}$ and $13.5 \mathrm{t}$ of $\mathrm{CaCO}_{3}$ in the fall of 1973 (Fig. 1a); together these provided a calculated addition of $477 \mu$ eq $\mathrm{L}^{-1}$ of acid neutralizing capacity (Yan and Dillon, 1984). Scheider et al. (1975) and Dillon et al. (1979) describe these additions and their immediate effects in detail. Additions were designed to raise the lake $\mathrm{pH}$ to 8 , immediately, and $\mathrm{pH}$ did indeed approach this target (Fig. 2a). Clearwater Lake was maintained as a control for the Middle Lake and other Sudbury liming studies (Scheider et al., 1975). As part of subsequent re-greening programs in the city (Lautenbach, 1987), crushed limestone was added to the watershed of Middle Lake in the mid-1980s (Fig. 1b), and this helped to maintain its circum-neutral $\mathrm{pH}$. While liming immediately raised the $\mathrm{pH}$ of Middle Lake (Fig. 2a), dramatically lowering metal levels (Fig. 2 b,c), the acidity and metal levels of Clear- water Lake also fell, but much more gradually (Fig. 2) in response to dramatic reductions of local smelter emissions (Keller et al. 1999). To date, annual local $\mathrm{SO}_{2}$ emissions have been reduced by over $90 \%$ from their peak values of 2.0 to 2.5 million tonnes $\mathrm{yr}^{-1}$, and the benefits for local watersheds have been dramatic (Gunn, 1995). While the $\mathrm{pH}$ of Middle Lake has now been non-toxic for 40 years, the $\mathrm{pH}$ of Clearwater Lake rose above 6, the threshold of acidification damage (Holt et al., 2003), only in 1999. Both $\mathrm{Cu}$ and $\mathrm{Ni}$ levels were dramatically lowered by the liming of Middle Lake (Fig. 2 b,c). Ni levels have fallen continuously (Fig. 2c), but still remain above the Canadian Water Quality Guideline of $25 \mu \mathrm{g} \mathrm{L}^{-1}$. Cu levels more or less stabilized in the two lakes in the mid-1990s (Fig. 2b) at near provincial Water Quality Guideline levels in Clearwater Lake, but still about 3 times these levels in Middle Lake.

Middle and Clearwater lakes have been visited by lake sampling crews on at least a monthly basis during the open-water season since 1973, and by fish sampling crews every few years. Routine sampling includes the generation of mid-lake temperature and oxygen profiles, the collection of phytoplankton and chlorophyll samples through the euphotic zone, and water quality (i.e., chemistry) samples taken as bathymetrically-weighted composites of all depths. Crustacean zooplankton were sampled on a weekly or fortnightly basis before 1980 , and on a monthly basis during the ice-free season since that time. Yan and Strus (1980), Yan et al. (1996a) and Palmer et al. (2013) describe the methods in detail. In brief, zooplankton were collected using non-metered tow nets in the early 1970s, a 34-L plexiglass trap in the late $1970 \mathrm{~s}$, and a $12.2 \mathrm{~cm}$ diameter, $76 \mu \mathrm{m}$ mesh, DRC net (McQueen and Yan 1993), thereafter. Yan and Strus (1980) demonstrated that gear changes
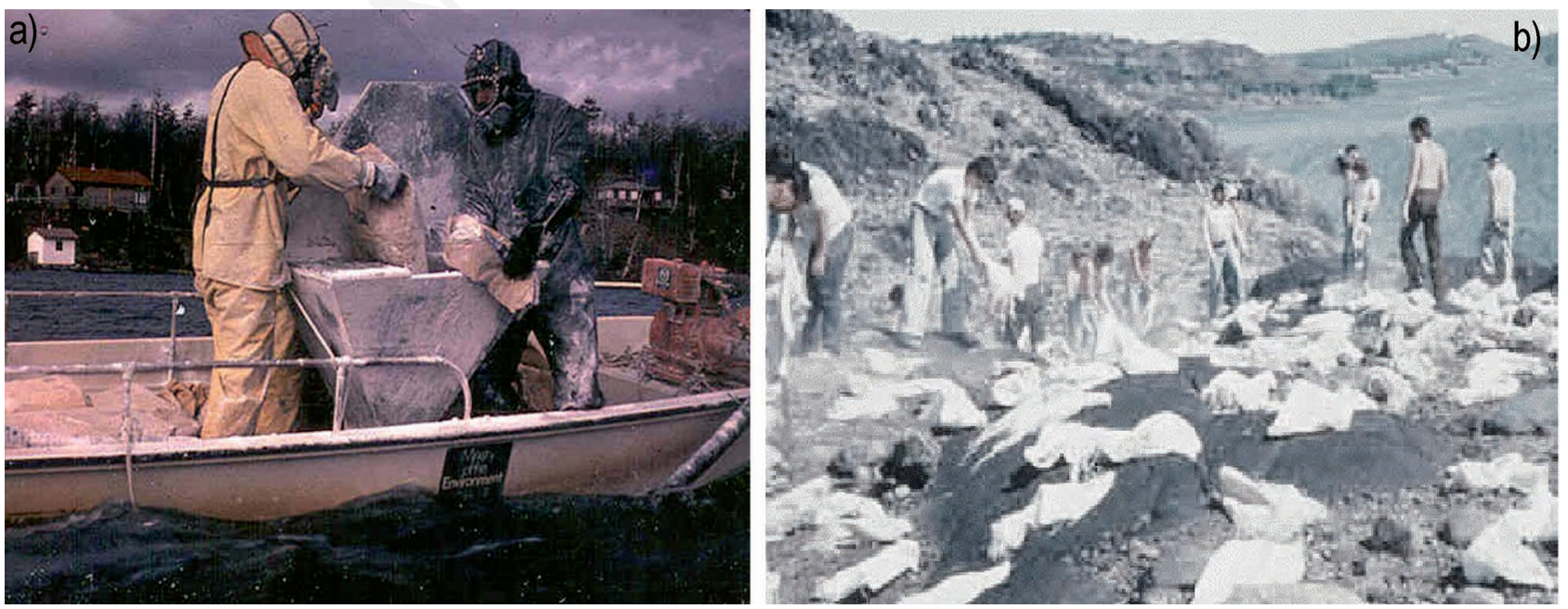

Fig. 1. Photographs of the liming of Sudbury lakes and watersheds. a) Addition of crushed limestone to a boat-mounted hopper during the liming of Middle Lake, Sudbury, in the summer of 1973. b) Example of hand-liming of the watershed of a Sudbury urban lake. 
did not confound interpretation of the zooplankton data prior to 1980, and Johannsson et al. (1992) proved that the difference between the trap and DRC net collections while statistically significant were orders of magnitude smaller than the changes observed over time in the abundances of zooplankton in Middle and Clearwater lakes. Since 1980, the sampling and preservation, and subsequent subsampling and counting protocols have been consistent in the lakes. Samples have been generated at a single mid-lake station at approximately the location of the maximum depth by combining the contents of 4 vertical hauls selected so that the fraction of the lake's volume contributed by each depth stratum approximates that stratum's contribution to the composite sample. The hauls were taken from 4, 8, 13 and $1 \mathrm{~m}$ above bottom (mab) in Clearwater Lake, generally $19 \mathrm{~m}$, and in Middle Lake, from 3, 6, 10 and 1 mab, generally $13 \mathrm{~m}$. Net filtration efficiency averaged above $80 \%$ at all times. Since 1980, a minimum of 250 animals have been counted and identified in each sample, subsampling to ensure that no one species contributed more than $10 \%$ of the count. With 35 years of data since 1980, and 6 samples per year, from each of which were identified at least 250 animals, more than 52,000 animals have been identified in samples in each lake since 1980, with many more counted during the 1970s.

In part, to help determine what factors might be limiting the persistence of colonizing zooplankton in the lakes we assessed the populations of fish in the lakes, and we modelled the metal toxicity of the lake waters. Since 2003, the fish communities of the lakes have been assessed using the Nordic Index Netting protocol (Appelberg, 2000; Morgan and Snucins, 2005). This depth-stratified, volume-weighted netting procedure using multi-mesh gillnets was developed in Scandinavia and has been used extensively across northeastern Ontario to assess the species richness, relative abundance and biomass of fish species, and to provide biological information on fish population status (Morgan and Snucins, 2005). Pre-2003 surveys in the lakes used a variety of gear (minnow traps, seines, small mesh trapnets and gillnets) to simply confirm presence or absence of fish in these study lakes. We modelled the trends of potential metal toxicity in the lakes using a toxic unit (TU) approach calculated from the sum of potential $\mathrm{Cu}, \mathrm{Ni}$ and $\mathrm{Zn}$ acute toxicity to zooplankton in the lakes, as described by Khan et al. (2012). In brief, we used a Biotic Ligand Model (BLM; HydroQual ver. 2.3.3) to calculate estimates of theoretical acute toxicity thresholds for each metal using the measured lake chemistry parameters over time. The individual TU for each metal was the ratio of the BLM-derived toxic threshold with the measured ambient metal concentration in each lake for each year; the individual TU's for the three metals were summed. Cumulative TU's $>1$ suggested that the lake waters were toxic to zooplankton, assuming individual metal effects were additive.

\section{Univariate community richness metrics: identifying the recovery bottlenecks}

Univariate measures of community species richness have been reliable indicators of both damage (Sprules, 1975; Locke, 1992) and recovery (Yan et al., 1996a, Keller and Yan, 1991, Palmer et al., 2013) of zooplankton from
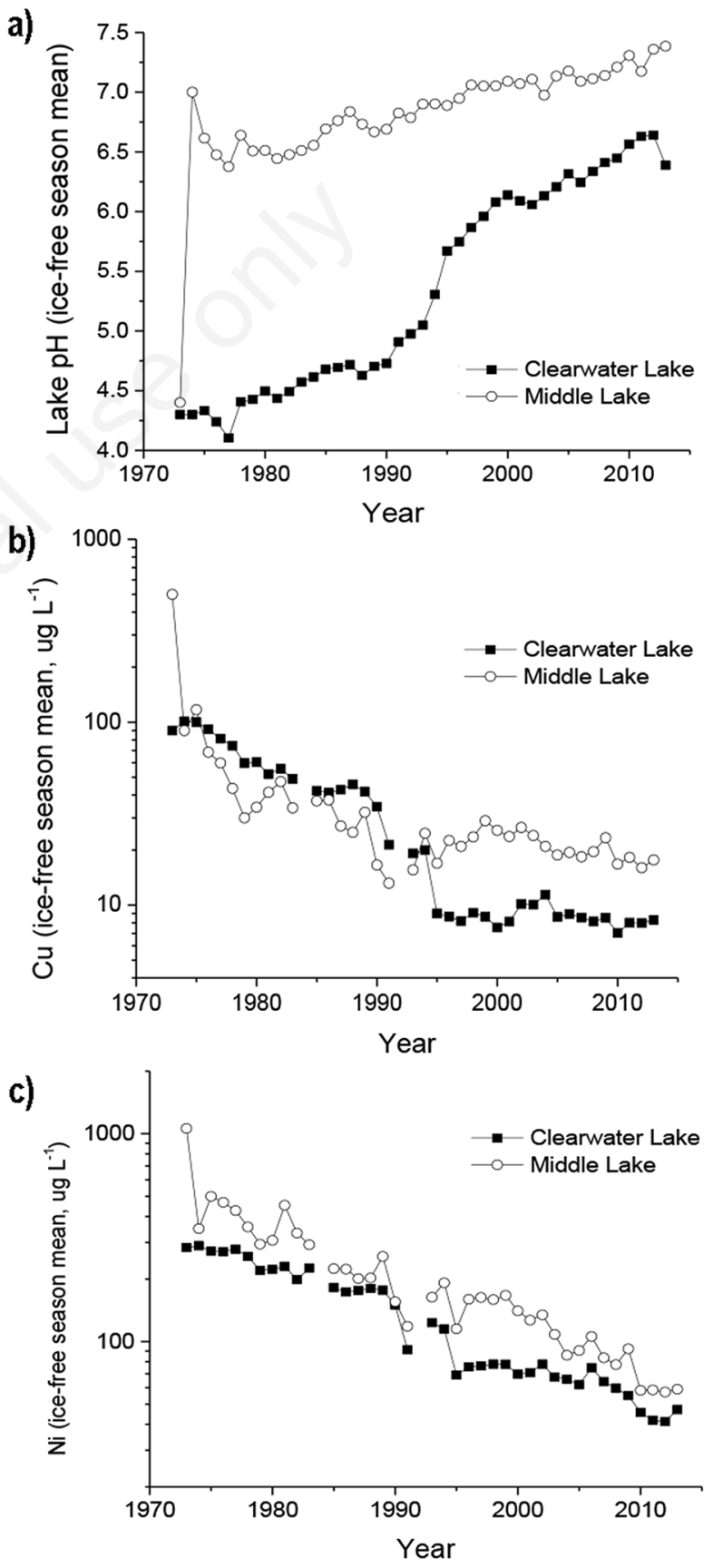

Fig. 2. Long-term changes in the water quality of Clearwater and Middle lakes averaged over the ice-free season. a) pH. b) Dissolved total $\mathrm{Cu}$. c) Dissolved total Ni. 
acidification and metal pollution. Among several possible richness metrics (Arnott et al., 1998), total annual richness, $\mathrm{S}_{\mathrm{T}}$, (i.e., the total number of taxa observed in a year) is not particularly useful as an overall recovery metric as it continues to rise with increasing sampling frequency (Rigler, 1982; Arnott et al., 1998 and 1999), and is insensitive to the annual persistence of species, a factor we wished to incorporate in a recovery metric. However, assuming constant counting procedures, average richness, $\overline{\mathrm{S}}$, i.e., the average number of species observed in counts of daily composite collections during the year, is a parameter that stabilizes very rapidly with increasing sample size (Keller and Yan, 1991), and responds strongly and quite predictably to acid and metal pollution. Given this stability and high signal to noise ratio it has been a metric much used to quantify recovery of zooplankton from acidification and metal pollution (Keller and Yan, 1991, Yan et al., 1996a, Palmer et al., 2013; Khan et al., 2012, Stockdale et al., 2014). No single metric can provide a comprehensive picture of community damage and recovery, and multivariate metrics are more sensitive than univariate metrics (Yan et al., 1996a) for detecting change. Nonetheless, in our search for a balance of simplicity, stability, and sensitivity, we employed average richness, $\overline{\mathrm{S}}$, to assess the overall trend of damage and recovery of the zooplankton of Middle and Clearwater lakes in comparison with a recovery target of 9-16 species collection ${ }^{-1}$, taken from Palmer et al. (2013). We fit a linear regression to the annual trends of $\overline{\mathrm{S}}$, comparing the slopes of the regression to quantify the recovery rate of richness in Middle and Clearwater lakes, and the departure from the Palmer et al. recovery target to assess the degree of recovery in the two lakes.

Recovery of communities that were as disturbed as our two study lakes requires colonists of most species to arrive, survive and thrive (Yan et al., 2003), and in Sudbury area lakes these three required steps are a function, respectively, of: i) natural and human assisted dispersal; ii) habitat quality, especially lingering toxicity from acidity and metals; and iii) predation by planktonic macro-invertebrates (Yan et al., 1991) or planktivorous fish (Webster et al., 2014; Gray et al., 2012). Each of these is difficult to quantify if we must do it for all variants of all colonizing species. However, our main interest was not in absolute estimates of these mechanisms, but comparative estimates, and this we can do given that the data have been generated in a consistent fashion for both lakes for many years. Here we compared the long-term species accumulation curves generated from the 40 annual species matrices of Clearwater and Middle lakes as a minimum estimate of species arrival. We hypothesized that the curve would rise more steeply for Clearwater than Middle Lake because it is larger, and has more human dwellings, and thus should have both more natural and anthropogenic propagules. We then estimated annual persistence of species $(\mathrm{P})$ as an estimator of whether propagules that survived introduction, also thrived that year, where:

$$
\mathrm{P}=1-\left(\left(\mathrm{S}_{\mathrm{T}} \overline{\mathrm{S}}\right) / \mathrm{S}_{\mathrm{T}}\right)
$$

This simple metric, which ranges from $0-1$, tracks the fraction of species found in each year that were actually encountered in each sample throughout the ice free season, i.e. were abundant enough that we saw them in our counts. P approaches 0 if the majority of species were found only once, and equals 1 if all species are found in every sample. In the latter case we take this as evidence that the populations have survived and are thriving in the community. Where persistence is low, species appear in the community, but for some reason many do not persist in the community that year at abundances we could detect. Arnott and Yan (2002) provided just such an example for Swan Lake, near Sudbury. Total richness was actually quite high in Swan Lake a year following a drought-induced acidification event, but persistence was unusually low that year, slowing recovery of community richness.

\section{RESULTS}

Average, daily, crustacean zooplankton richness $(\overline{\mathrm{S}})$ increased in Middle and Clearwater lakes from 1973 to 2014, and the regression slopes indicated the rate of increase of $\overline{\mathrm{S}}$ averaged 0.9 taxa decade ${ }^{-1}$ in Clearwater Lake, much below the rate of 1.6 species decade ${ }^{-1}$ in Middle Lake (Fig. 3). $\overline{\mathrm{S}}$ reached 9 spp. sample ${ }^{-1}$ in 2006 in Middle Lake (Fig. 3), a value within the Palmer recovery target of 9 to $16 . \overline{\mathrm{S}}$ has not yet reached this target in Clearwater Lake, peaking at 7.8 spp. collection $^{-1}$ in 2008 (Fig. 3).

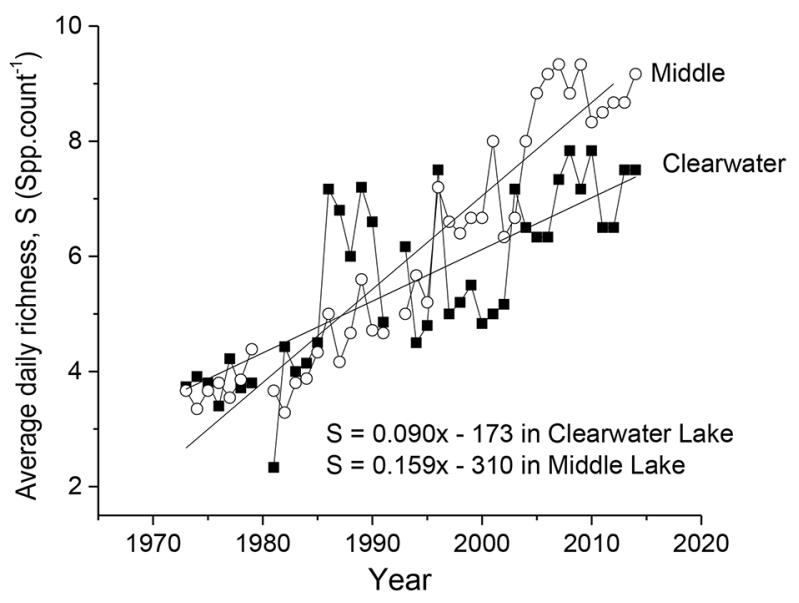

Fig. 3. Comparison of 40 year trend in average richness, $\bar{S}$ (species daily collection ${ }^{-1}$ averaged over the ice-free season) of the crustacean zooplankton communities of Middle and Clearwater lakes. 
Based on the use of the Palmer et al. (2013) target of 916 , or the earlier target of 8-12 species developed by Yan et al. (1996a) using 1980s zooplankton data from reference lakes, richness in Middle Lake has recovered, while it has not yet recovered in Clearwater Lake.

The slower and less complete recovery of richness in Clearwater Lake does not appear to be attributable to lack of colonists. More species have actually been recorded in Clearwater Lake than in Middle Lake (Fig. 4), and the slope of the species accumulation curve is steeper in Clearwater Lake earlier in the record, when the lake's water quality was quite poor. Indeed given that Arnott et al. (1999) detected only 36 species of crustacean zooplankton in a suite of limnologically similar lakes in south-central Ontario, it would appear that most potential colonists from the meta-community have been detected in Clearwater Lake with its 40 species, while more species may yet appear in Middle Lake. To date, over the 40 year period only 30 species have been detected in Middle Lake (Fig. 4).

While more species have appeared in Clearwater Lake than in Middle Lake, their annual persistence has been much lower than in Middle Lake for the majority of years in the record. Annual persistence averaged $73 \%$ in Middle lake, significantly higher than the $56 \%$ in Clearwater Lake (paired $\mathrm{t}=7.78, \mathrm{P}<0.001$ ). Annual persistence was greater in Clearwater Lake in only 6 of the 40 years (Fig. 5). It did not change over time ( $\mathrm{P}>0.25$ in linear regressions for either lake), which is perhaps surprising given the time trends in water quality (Fig. 2), nor did the difference in annual persistence between the two lakes change over time (regression $\mathrm{F}=1.7, \mathrm{P}=0.2$ ). Rather than annual persistence increasing more rapidly in Middle than in Clearwater Lake, or changing over time more in one than the other lake, it was simply higher in most years in Middle Lake than in Clearwater Lake.

This suggests that $\overline{\mathrm{S}}$ has increased more rapidly in Middle Lake than in Clearwater Lake, not because more colonists have arrived, but because those colonists that arrived have persisted, i.e., they have survived and thrived more often in Middle Lake than in Clearwater Lake.

\section{DISCUSSION}

The comparison of species accumulation curves suggests that recovery of average species richness in Middle and Clearwater lakes has not been limited by colonist arrival. Recovery of richness has lagged in Clearwater Lake, even though many, perhaps most possible species (Arnott et al., 1998), have arrived in the lake. We can not know from where they came, without detailed genetic research, but possibilities abound. Paleolimnological data suggest zooplankton communities were richer before industrial development (Labaj et al., 2014, 2015), hence, hatching of long-lived resting eggs is one possibility. Daphniid resting eggs can live for centuries (Weider et al., 1997), and can be quite abundant in the recent sediments of Sudbury's urban lakes (Yan et al., 1996b; Pollard et al., 2003). Secondly, there are 100's of lakes in the municipality of Sudbury, and colonists can spread rapidly among neighbouring water bodies by many natural mechanisms (Cáceres and Soluk, 2002; Incagnone et al., 2015). Finally, there are many people in this suburban landscape that can move propagules. Kelly et al. (2013), for example, found 15 different species of crustacean zooplankton in water collected from 63 recreational boats leaving Lake Simcoe, Ontario, by water, over only two summer weekends. Gray et al. (2012) demonstrated that dispersal may

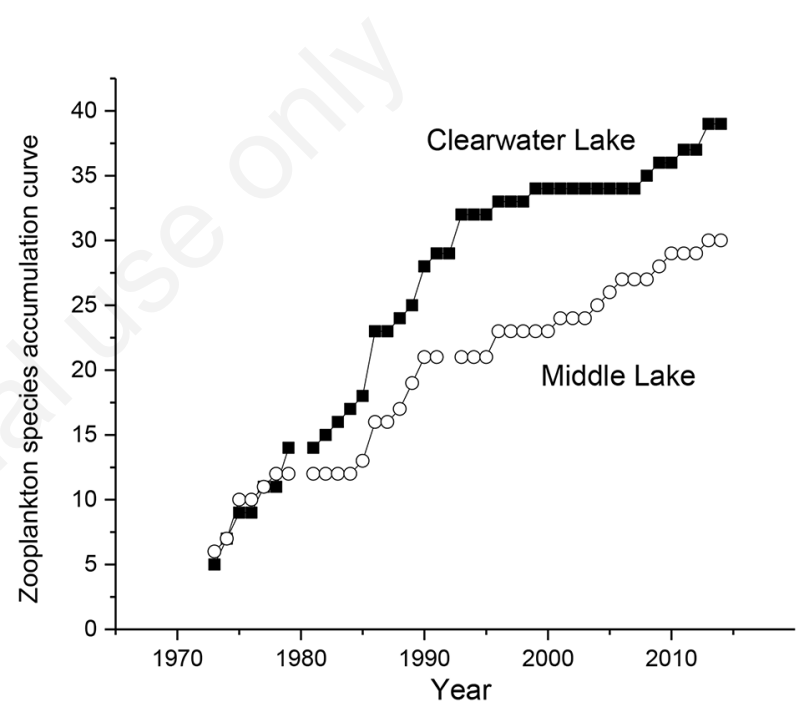

Fig. 4. Long-term trend in the annual species accumulation curves of crustacean zooplankton in Middle and Clearwater Lakes.

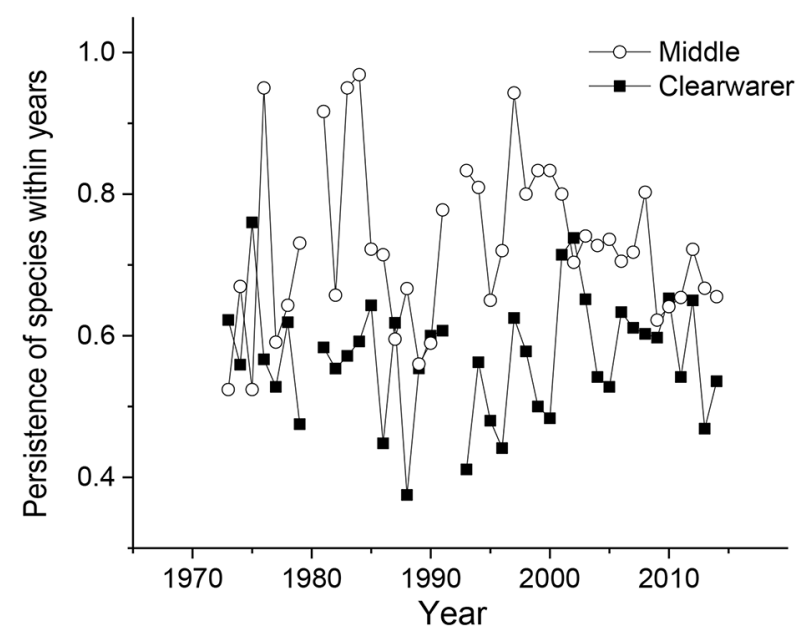

Fig. 5. Comparison of long-term changes in the annual persistence of species in Middle and Clearwater Lakes. 
in fact limit the recovery of copepods in lakes in Killarney Provincial Park, south west of Sudbury, but suburban Sudbury is far less rugged than Killarney, and has far more people, perhaps accounting for this difference.

Average species richness has increased more rapidly in Middle than in Clearwater Lake because while fewer species arrived, they tended to persist each year. There are two probable explanations for their better annual persistence in Middle Lake. First, the toxic threat from both acidity and metals was more conducive to the survival of colonists in Middle than in Clearwater Lake. Liming immediately raised the $\mathrm{pH}$ of Middle Lake waters from levels lethal to most zooplankton (Keller et al., 1990; Havens et al., 1993), i.e., from 4.4 to near circum-neutrality (Fig. 2a), while $\mathrm{pH}$ remained at toxic levels in Clearwater until at least the mid-1990s. Even though Ni levels were higher in Middle lake in all years, and $\mathrm{Cu}$ levels were higher in Middle Lake in the last 20 years, the sum of the Toxic Units of $\mathrm{Cu}, \mathrm{Ni}$ and $\mathrm{Zn}$ incorporating biotic ligand model estimates of toxic thresholds clearly indicated metals were not as toxic in Middle Lake as in Clearwater Lake after 1975. Indeed, the higher $\mathrm{pH}$ and resultant lower free metal availability, the higher competing base cation, especially $\mathrm{Ca}$, levels, and higher dissolved organic carbon (DOC) levels of Middle Lake rendered its waters, in theory, orders of magnitude less toxic from metals than those of Clearwater Lake from the late 1970s to the mid-1990s (Fig. 6), and the modelled Toxic Unit threshold of 1 was reached in Middle Lake 6 years earlier than in Clearwater Lake (Fig. 6). While the huge disparity in modelled toxicity between lakes declined over time, Clearwater Lake waters remain theoretically more toxic to this day (Fig. 6), and on one occasion this theoretical difference has been confirmed in a compar-

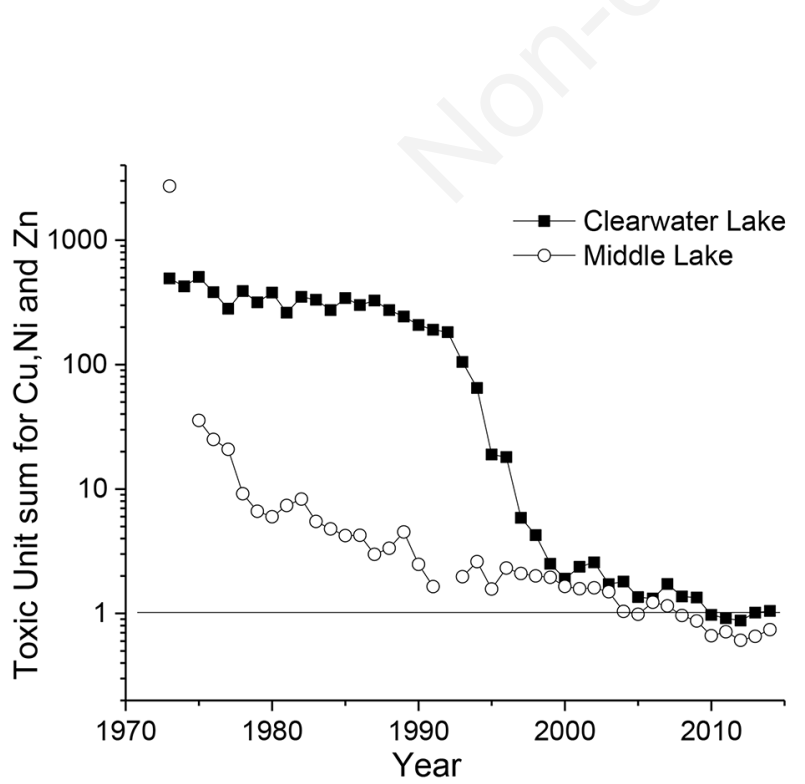

Fig. 6. Long-term changes in the calculated sum of the toxic units of $\mathrm{Cu}, \mathrm{Ni}$ and $\mathrm{Zn}$ in Middle and Clearwater Lakes. ative bioassay. In 2007, Celis-Salgado et al. (2016) assessed the toxicity of filtered epilimnetic waters from Middle and Clearwater lakes to a single clone of each of four Daphnia species (D. pulex, pulicaria, mendotae and ambigua) that had been isolated from soft-water lakes in Ontario. Mortality was complete for all four species in the Clearwater Lake assays over 14 days, while Middle Lake waters were less toxic for three of the species, permitting 90,80 and $40 \%$ survival of the $D$. pulex, D. pulicaria and mendotae clones, respectively. Such lower inherent ambient toxicity would likely have reduced mortality and fostered persistence of colonists arriving each year in Middle Lake in comparison with those arriving in Clearwater Lake.

Yan et al. (2004) could not distinguish between metal toxicity and heavy planktivory as explanations for the delayed recovery of Cladocera in Middle Lake up to 2003. More recent work has confirmed that both mechanisms may indeed limit the recovery of Cladocera from historical damage in Killarney Provincial Park (Gray et al., 2012), and in formerly contaminated lakes closer to Sudbury (Valois et al., 2010 and 2011; Webster et al., 2013). That work suggests that complete zooplankton recovery does not occur in Sudbury's urban lakes until both water quality permits it, and re-invading piscivores have reduced what would previously have been massive populations of planktivorous fish. Both mechanisms may have played at role in the temporal dynamics of richness in Middle Lake. Colonist persistence was higher in Middle Lake throughout the 4 decade record. Lower acidity and metal toxicity probably accounts for this observation from the early 1980 s to the early 2000s. More recently, reduced planktivory may have also contributed. Fish likely disappeared from Middle and Clearwater lakes in the 1930's when the first tall smelter stacks were constructed, and pollutants were dispersed across the urban landscape (Yan and Miller, 1984). Fish were absent from the lakes when our research began in 1973 (Scheider et al., 1975). Intermittent fish surveys since that time first document the return of planktivores to Clearwater Lake in the late 1990s, and piscivorous bass were absent until approximately 2014 (Fig. 7). By contrast plantivorous yellow perch (Perca flavescens) colonized Middle Lake a decade earlier in the late 1980s, and multi-species piscivorous community (northern pike, Esox lucius), walleye (Sander vitreus) and bass appeared in the collections regularly since 2004 (Luek et al., 2010, 2013 and Fig. 7). Once they arrive, predatory piscivores rapidly reduce planktivore standing stocks in Sudbury lakes (Lippert et al., 2007; Luek et al., 2013; Gunn unpubl. data), but the timing of the predator control on the planktivores was much earlier in Middle Lake than in Clearwater Lake (Fig. 7). We therefore hypothesize that it was metal and acid toxicity that was principally responsible for the comparatively low annual persistence of zooplankton colonists in Clearwater Lake 
up until 2000, but heavy predation from the large population of planktivorous yellow perch further reduced annual persistence since that time.

If our inferences about the dominant mechanisms regulating recovery in these lakes are correct, there are clear implications for management, should a recovered zooplankton assemblage be a management goal. First, there is no need to introduce zooplankton propagules to lakes. In urban landscapes, they will arrive unaided, in sufficient numbers to restore zooplankton assemblages. Colonist arrival rates are not the key recovery bottleneck. Second, the focus of management should be on both the restoration of habitat quality, and the introduction of piscivores in lakes that previously supported them. Restoring habitat quality on its own will likely not be sufficient to permit zooplankton recovery.

In our use of the three recovery metrics - richness, species accumulation, and annual persistence - we have made simplifying assumptions, which we believe were unavoidable. Our species accumulation curves almost certainly have underestimated colonist arrival rates, because species are detected not when the first few colonists arrive, but when there are enough to be both captured by our sampling gear, and encountered in subsamples. Hence, the number of founding colonists, their initial rates of growth, their spatial distribution, and our counting protocol all influence detection. There will therefore be false negatives in species accumulation. We must accept two facts. First, it is impossible to detect all arriving zooplankton colonists, and second, the detection of rare species is a nagging problem that plagues all research on community assembly, if not all community ecology (Rigler, 1982). There are approaches to estimate the resulting census error (White, 2004), but we have not used them in our analyses, largely because our interest was comparative not absolute, and the methods we used in the two lakes were very consistent over the last 30 years of record.

We are not aware of previous uses of the annual persistence metric we developed, although it would not surprise us if has been previously used, as it is so simple to calculate and it has intuitive appeal. If animals are consistently detected, i.e. they are persistent, they must be relatively abundant in the assemblage, and they are likely serving some function in the community. Of course this is a univariate metric which takes no account of species composition. But it does tell us that the species that are there have survived initial colonization and are thriving in the community. This is what we wished the metric to do. As in previous work (Yan et al., 1996a), we would not recommend making broad statements about recovery from any single metric. Still we do support the use of average richness as one good univariate metric to assess damage and recovery from acidification and metal pollution. Ongoing research on Sudbury lakes continues to provide valuable lessons, both fundamental and applied, about the damage and recovery of lakes from acid and metal pollution. However, the lessons are to an extent, site specific. Recovery of acid lakes in Killarney Provincial Park (Gray et al., 2012) appears to depend on somewhat different mechanisms than those in Sudbury's suburban landscape. The greater metal levels of the urban lakes have certainly posed an additional ecological hurdle to the recovery process, and we are learning (Luek et al., 2010; Valois et al., 2010, 2011; Webster et al., 2013) that the recovery of any one component of the food web may well depend on the recovery not just of aquatic habitat quality,
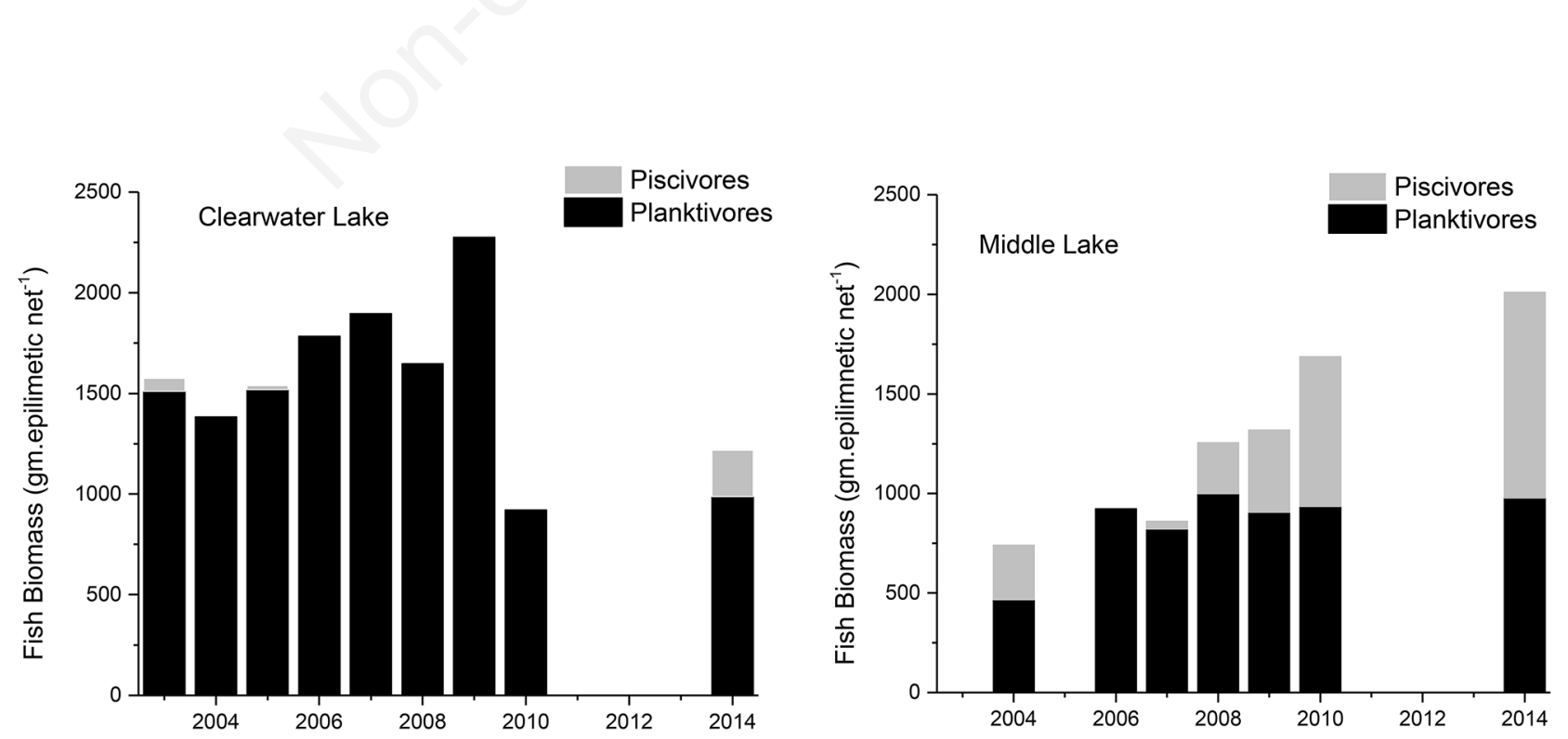

Fig. 7. Biomass (g wet weight epilimnetic net ${ }^{-1}$ ) of planktivorous and piscivorous fish species in Clearwater and Middle Lakes assessed with multiple Nordic net sets since 2003 . 
but also of other components of the food web, both in the lake, and beyond its borders in the watershed (Tanentzap et al., 2014). Here, we have added to this body of knowledge by demonstrating that simple manipulations of zooplankton species presence/absence matrices can provide useful information on the mechanistic bottlenecks to the recovery process, information that is quite useful for managers. Annual persistence of colonists clearly varies over time in some Sudbury lakes (Arnott and Yan, 2002). Here we have shown that differences among lakes in this annual persistence can be substantial and long-lasting, and can influence the recovery of average species richness, a particularly valuable bioindicator of ecological condition.

\section{CONCLUSIONS}

Thousands of lakes in the Sudbury area were acidified and contaminated with metals originating from local mining and particularly from local smelter operations over the last century. For Sudbury's urban lakes and lakes close to the smelters, the contamination was particularly severe, and many local populations of biota were extirpated. Since the 1970s, emissions have been dramatically reduced and there have been tremendous benefits for local lakes (Gunn, 1995). Nevertheless, metal contamination lingers to this day, especially in urban lakes that are only a few $10 \mathrm{~s}$ of $\mathrm{km}$ from the smelters. The recovery of biota in these lakes requires that colonists of extirpated species arrive, survive, and subsequently thrive. For zooplankton, this is not guaranteed, because while zooplankton do disperse quite well in the Sudbury area (Audet et al., 2013), various ecological, toxicological or biogeographic processes (reviewed by Incagnone et al. 2015) may restrict local colonization success. We examined 4 decades of zooplankton sampling records from two of Sudbury's urban lakes, Middle and Clearwater lakes, the former of which was limed in 1973. Even though Middle Lake is smaller and less developed than Clearwater Lake, which we hypothesized should lower propagule introduction rates, and more heavily contaminated with metals, which we might have thought would lower propagule survival, community richness has recovered in Middle Lake, but not, as yet, in Clearwater Lake. A comparison of species accumulation curves in the two lakes did indicate that more propagules were indeed likely arriving in Clearwater than in Middle Lake, but a simple metric assessing annual persistence suggested that these colonists were prospering in Middle Lake more than than in Clearwater Lake. The greater annual persistence in Middle Lake was correlated first with better habitat quality, i.e. less metal toxicity and higher $\mathrm{pH}$ after liming. We hypothesized that smaller planktivore populations in Middle Lake over the last decade also promoted annual persistence of colonists.

There is still much to be learned about the pace, extent, and regulators of recovery of zooplankton from acid- ification and metal pollution, or indeed from other anthropogenic disturbances (Verdonschot et al., 2013). In the particular case of Sudbury's lake-rich, suburban landscape, recovery does not appear to depend strongly on propagule introduction rates, but rather on their persistence, and this persistence is controlled both by abiotic and biotic pressures which can vary both among lakes and among years.

\section{ACKNOWLEDGMENTS}

We thank Lynne Witty and Bill and Dee Geiling for processing plankton samples, Jocelyne Heneberry for field and database assistance, Farhan Khan for contributions to biotic ligand models, the Ontario Ministry of Natural Resources, Ontario Ministry of the Environment and Climate Change for logistical and financial support, the Natural Sciences and Engineering Council of Canada and the Italian Institute for Ecosystem Studies for financial support.

\section{REFERENCES}

Appelberg M, 2000. Swedish standard methods for sampling freshwater fish with multi-mesh gillnets. Fiskeriverket Information 1:3-32.

Arnott SE, Magnuson JJ, Yan ND, 1998. Crustacean zooplankton species richness: single and multiple year estimates. Can. J. Fish. Aquat. Sci. 55:1573-1582.

Arnott SE, Yan ND, Magnuson J, Frost TM, 1999. Inter-annual variability of biodiversity: species overturn of zooplankton in lakes. Can. J. Fish. Aquat. Sci. 56:162-172.

Arnott SE, Yan ND, 2002. The influence of drought and re-acidification on zooplankton emergence from resting stages. Ecol. Applicat. 12:138-153.

Audet C, MacPhee S, Keller W, 2013. Constructed ponds colonized by crustacean zooplankton: local and regional influences. J. Limnol. 72:524-530.

Bonacina C, 2001. Has Lake Orta completely recovery from its heavy polluted condition? A seventy years long history. J. Limnol. 60:285-287.

Cáceres CE, Soluk DA, 2002. Blowing in the wind: a field test of overland dispersal and colonization by aquatic invertebrates. Oecologia 131:402-408.

Celis-Salgado MPG, Keller W, Yan ND, 2016. Calcium and sodium as regulators of the recovery of four Daphnia species along a gradient of metals and base cations in metal-contaminated lakes in Sudbury, Ontario, Canada. J. Limnol. 75 (Suppl.2):36-49.

Clair TA, Hindar A, 2005. Liming for the mitigation of acid rain effects in freshwaters: a review of recent results. Env. Rev. 13:91-128.

Dillon PJ, Yan ND, Scheider WA, Conroy N, 1979. Acidic lakes in Ontario, Canada: characterization, extent and responses to base and nutrient additions. Arch. Hydrob. Beih., Ergebn. Limnol. 13:317-336.

Gray DK, Arnott SE, 2009. Recovery of acid damaged zooplankton communities: measurement, extent and limiting factors. Env. Rev. 17:81-99.

Gray DK, Arnott SE, Shead JA, Derry AM, 2012. The recovery 
of acid-damaged zooplankton communities in Canadian lakes: the relative importance of abiotic, biotic and spatial variables. Freshwater Biol. 57:741-758.

Gunn JM, 1995. Environmental restoration and recovery of an industrial region. Springer, New York: $358 \mathrm{pp}$.

Gunn JM, McMurtry MJ, Casselman JM, Keller W, Powell MJ, 1988. Changes in the fish community of a limed lake near Sudbury, Ontario: effects of chemical neutralization, or reduced atmospheric deposition of acids? Water Air Soil Poll. 41:113-1376.

Havens KE, Yan ND, Keller W, 1993. Lake acidification effects on crustacean zooplankton populations. Env. Sci. Technol. 27:1621-1624.

Holt CA, Yan ND, Somers K, 2003. pH 6 as the threshold to use in critical load modelling for zooplankton community change with acidification in lakes of south-central Ontario: accounting for morphometry and geography. Can. J. Fish. Aquat. Sci. 60:151-158.

Incagnone G, Marrone F, Barone R, Robba L, Naselli-Flores L, 2015. How do freshwater organisms cross the "dry ocean"? a review on passive dispersal and colonization processes with a special focus on temporary ponds. Hydrobiologia 750:103-123.

Johannsson OE, Shaw MA, Yan ND, Filion J-M, Malley DA, 1992. A comparison of freshwater zooplankton sampling gear: nets, traps and submersible pump. Can. Tech. Rep. Fish. Aquat. Sci. No. 1894: 29 pp.

Keller W, Gunn JM, Yan ND, 1999. Acid rain - perspectives on lake recovery. J. Aquat. Ecosys. Stress Recov. 6:207-216.

Keller W, Yan ND, 1991. Recovery of crustacean zooplankton species richness in Sudbury area lakes following water quality improvements. Can. J. Fish. Aquat. Sci. 48:1635-1644.

Keller W, Yan ND, 1998. Biological recovery from lake acidification: zooplankton as a model of patterns and process. Restoration Ecol. 6:364-375.

Keller W, Yan ND, Holtze KE, Pitblado JR, 1990. Inferred effects of lake acidification on Daphnia galeata mendotae. Env. Sci. Technol. 24:1259-1261.

Kelly NE, Wantola K, Weisz E, Yan ND, 2013. Recreational boaters as a vector of secondary spread for aquatic invasive species and native crustacean zooplankton. Biol. Invasions 15:509-519.

Khan F, Keller W(B), Yan ND, Welsh P, Wood C, McGeer J, 2012. Application of biotic ligand and toxic unit modeling approaches to predict improvements in zooplankton species richness in smelter-damaged lakes near Sudbury, Ontario. Environ. Sci. Technol. 46:1641-1649.

Labaj AL, Jeziorski A, Kurek J, Smol JP, 2014. Long-term trends in Cladoceran assemblages related to acidification and subsequent liming of Middle Lake (Sudbury, Canada). Water Air Soil Poll. 225:1868.

Labaj AL, Kurek J, Jeziorski A, Smol, JP, 2015. Elevated metal concentrations inhibit biological recovery of Cladocera in previously acidified boreal lakes. Freshwater Biol. 60:347-359.

Lautenbach WE, 1987. The greening of Sudbury. J. Soil Water Conserv. 42:228-231.

Lippert KA, Gunn JM, Morgan GE, 2007. Effects of colonizing predators on yellow perch (Perca flavescens) populations in lakes recovering from acidification and metal stress. Can. J. Fish. Aquat. Sci. 64:1413-1428.
Locke A, 1992. Factors influencing community structure along stress gradients: zooplankton responses to acidification. Ecology 73:903-909.

Luek A, Morgan GE, Wissel B, Gunn JM, Ramcharan CW, 2010. Rapid and unexpected effects of piscivore introduction on trophic position and diet of perch (Perca flavescens) in lakes recovering from acidification and metal contamination. Freshwater Biol. 55:1616-1627.

Luek A, Morgan GE, Wissel B, Gunn JM, Ramcharan CW, 2013. Impaired littoral energy pathways cause a shift to pelagic resources by fish in recovering lake food webs. Ecol. Freshw. Fish. 22:348-360.

McQueen DJ, Yan ND, 1993. Metering filtration efficiency of fresh water zooplankton hauls: reminders from the past. J. Plankton Res. 15:57-65.

Palmer ME, Keller W (B), Yan ND, 2013. Gauging recovery of zooplankton from historical acid and metal contamination: the influence of temporal changes in restoration targets. J. Appl. Ecol. 50:107-118.

Pollard HG, Colbourne JK, Keller W, 2003. Reconstruction of centuries-old Daphnia communities in a lake recovering from acidification and metal contamination. Ambio 32:214-218.

Rigler FH, 1982. Recognition of the possible: an advantage of empiricism in ecology. Can. J. Fish. Aquat. Sci. 39:1323-1331.

Scheider WA, Adamski J, Paylor M, 1975. Reclamation of acidified lakes near Sudbury, Ontario. Ontario Ministry of the Environment Report, Dorset Environmental Science Centre, Dorset: $129 \mathrm{pp}$.

Sprules WG, 1975. Midsummer crustacean zooplankton communities in acid-stressed lakes. J. Fish. Res. Board Can. 32:389-395.

Stockdale A, Tipping E, Lofts S. Fott J, Garmo OA, Hruska J, Keller B, Löfgren S, Maberly SC, Majer V, NierzwickiBauer SA, Persson G, Schartau AK, Thackeray SJ, Valois A, Vrba J, Walseng B and Yan N. 2014. Metal and proton toxicity to lake zooplankton: a chemical speciation based modelling approach. Env. Pollut. 186: 115-125.

Svenson T, Dickson W, Hellberg J, Moberg G, Munthe N, 1995. The Swedish liming program. Water Air Soil Poll. 85:10031008.

Tanentzap AJ, Szkokan-Emilson EJ, Kielstra B, Arts MT, Yan ND, Gunn JM, 2014. Forests fuel fish growth in freshwater deltas. Nature Communications DOI: 10.1038/ncomms5077.

Valois A, Keller WB, Ramcharan C, 2010. Abiotic and biotic processes in lakes recovering from acidification: the relative roles of metal toxicity and fish predation as barriers to zooplankton re-establishment. Freshwater Biol. 55:2585-2597.

Valois A, Keller WB, Ramcharan C, 2011. Recovery in a multiple stressor environment: using the reference condition approach to examine zooplankton community change along opposing gradients. J. Plankton Res. 33:1417-1429.

Verdonschot PFM, Spears BM, Feld CK, Brucet S, Keizer-Vlek H, Borja A, Elliott M, Kernan M, Johnson RK, 2013. A comparative review of recovery process in rivers, lakes, estuarine and coastal waters. Hydrobiologia 704:453-474.

Webster NI, Keller WB, Ramcharan CW, 2013. Restoration of zooplankton communities in industrially damaged lakes: influences of residual metal contamination and the recovery of fish communities. Restor. Ecol. 21:785-792.

Weider LJ, Lampert W, Wessels M, Colbourne JK, Limburg P, 
1997. Long-term genetic shifts in a micrcrustacean egg bank associated with anthropogenic changes in the Lake Constance ecosystem. Proc. Biol. Sci. 264:1613-1618.

Weisz EJ, Yan ND, 2010. Relative value of limnological, geographic and human use variables as predictors of the presence of Bythotrephes longimanus in Canadian Shield Lakes. Can. J. Fish. Aquat. Sci. 67:462-472.

White EP, 2004. Two-phase species-time relationships in North American land birds. Ecol. Lett. 7:329-336.

Winter JG, Keller W, Paterson AM, Yan ND, 2008. Three decades of recovery of the phytoplankton community in Clearwater Lake (Sudbury, Canada) from acid and metal contamination. Verh. Int. Verein. Limnol. 30:247-252.

Yan ND, 1979. Phytoplankton of an acidified, heavy metal-contaminated lake near Sudbury, Ontario, 1973-1977. Water Air Soil Poll. 11:43-55.

Yan ND, Dillon PJ, 1984. Experimental neutralization of lakes near Sudbury, Ontario, p. 417-456. In: J. Nriagu (ed.), Environmental impacts of smelters. J. Wiley \& Sons, Toronto.

Yan ND, Girard R, Heneberry JH, Keller W(B), Gunn JM, Dillon PJ, 2004. Recovery of Copepod, but not Cladoceran, zooplankton from severe and chronic effects of multiple stressors. Ecol. Lett. 7:452-460.
Yan ND, Keller W, MacIsaac HJ, McEachern LJ, 1991. Regulation of zooplankton community structure of an acidified lake by Chaoborus. Ecol. Appl. 1:52-65.

Yan ND, Keller W, Somers KM, Pawson TW, Girard RE, 1996a. The recovery of crustacean zooplankton communities from acidification: comparing manipulated and reference lakes. Can. J. Fish. Aquat. Sci. 53:1301-1327.

Yan ND, Leung B, Keller W, Arnott SE, Gunn JM, Raddum GG, 2003. Developing a conceptual framework for the recovery of aquatic biota from acidification: a zooplankton example. Ambio 32:165-169.

Yan ND, Miller GE, 1984. Effects of deposition of acids and metals on chemistry and biology of lakes near Sudbury, Ontario, p. 244-282. In: J. Nriagu (ed.) Environmental impacts of smelters J. Wiley \& Sons, Toronto.

Yan ND, Strus R, 1980. Crustacean zooplankton communities of acidic, metal-contaminated lakes near Sudbury, Ontario. Can. J. Fish. Aquat. Sci. 37:2282-2293.

Yan ND, Welsh PG, Lin H, Taylor DJ, Filion J-M, 1996b. Demographic and genetic evidence of the long-term recovery of Daphnia galeata mendotae (Crustacea: Daphniidae) in Sudbury lakes following additions of base: the role of metal toxicity. Can. J. Fish. Aquat. Sci. 53:1328-1344. 